\title{
Impacts of building information modeling (BIM) implementa- tion on design and construction performance: a resource dependence theory perspective
}

C The Author(s) 2017. Published by Higher Education Press. This is an open access article under the CC BY license (http:// creativecommons.org/licenses/by/4.0)

\begin{abstract}
Drawing on resource dependence theory, this paper develops and empirically tests a model for understanding how the implementation of building information modeling (BIM) in construction projects impacts the performance of different project participating organizations through improving their interorganizational collaboration capabilities. Based on two sets of survey data collected from designers and general contractors in BIMbased construction projects in China, the results from partial least squares analysis and bootstrapping mediation test provide clear evidence that BIM-enabled capabilities of information sharing and collaborative decision-making as a whole play a significant role in determining BIMenabled efficiency and effectiveness benefits for both designers and general contractors. The results further reveal that designers and general contractors benefit from project BIM implementation activities significantly nonequivalently, and that this non-equivalence closely relates to the different roles played by designers and general contractors in BIM-enabled interorganizational resource exchange processes. The findings validate the resource dependence theory perspective of BIM as a boundary spanning tool to manage interorganizational resource dependence in construction projects, and contribute to
\end{abstract}

Received February 8, 2017; accepted March 9, 2017

Dongping CAO $(\bowtie)$

School of Economics and Management, Tongji University, Shanghai 200092, China; Department of Building and Real Estate, Hong Kong Polytechnic University, Hong Kong, China

E-mail: dongping.cao@connect.polyu.hk

Heng LI

Department of Building and Real Estate, Hong Kong Polytechnic University, Hong Kong, China

Guangbin WANG

Department of Management Science and Engineering, Soochow University, Suzhou 215006, China deepened understandings of how and why project participating organizations benefit differently from the implementation of interorganizational information technologies like BIM.

Keywords building information modeling, interorganizational collaboration, construction project performance, resource dependence theory, partial least squares modeling

\section{Introduction}

Construction projects worldwide have been plagued by a variety of performance problems such as design deficiency, cost overruns and schedule slippages (Zhang et al., 2008). As an innovative method of creating, sharing and utilizing project lifecycle data, building information modeling (BIM) has been increasingly regarded in the past decade as a promising technology to address these performance problems (Cao et al., 2016; Eastman et al., 2011; Li et al., 2009). Despite of the increasing research interest in this promising technology in recent years (Volk et al., 2014; Yalcinkaya and Singh, 2015), most of the extant empirical studies on the impacts of BIM implementation have focused on reporting descriptive statistics of the project benefits gained from BIM implementation activities in specific project contexts (e.g., Giel and Issa, 2013; Poirier et al., 2015). While these studies have valuably illustrated the uncertainty of the performance impacts of BIM implementation, scant scholarly attention has been further devoted to characterizing how the resultant project BIM benefits are influenced by related technology implementation characteristics in different project contexts and, therefore, shedding light on how to maximize the performance gains of project BIM implementation (Cao et al., 2015; Francom and El Asmar, 2015).

What is lacking in the extant literature also includes the 
empirical investigation of how different types of participating organizations benefit differently from project BIM implementation activities. Different from other technologies like two-dimensional computer-aided design (2D $\mathrm{CAD}$ ), BIM is a typical interorganizational innovation whose implementation process not only requires the cooperation of multiple project participating organizations but could also generate performance impacts spilling over organizational boundaries (Cao et al., 2015; Taylor, 2007). While research on interorganizational relationships in other industries suggests that perceived inequity in the allocation of collaborative benefits could substantially jeopardize related collaborative "pie-expansion" efforts (Scheer et al., 2003), extant research on the performance impacts of project BIM implementation in the construction industry has focused on assessing related performance gains from the perspective of a whole project (Francom and El Asmar, 2015; Smits et al., 2016) or a specific participating organization (Poirier et al., 2015; Sacks and Barak, 2008). By contrast, limited empirical evidence has been provided to characterize BIM implementation benefits gained by different project participating organizations in a comparative manner and thus offer insights into how to better address potential "pie-sharing" problems and incentivize collaborative "pie-expansion" efforts during project BIM implementation processes.

Drawing on resource dependence theory (Pfeffer and Salancik, 1978), this study aims to develop and empirically test a model for examining how project BIM implementation activities impact the performance of different project participating organizations from an interorganizational resource exchange perspective. Using resource dependence theory as a lens to understand BIM as a boundary spanning tool for project participating organizations to manage interorganizational dependence, the model specifically features BIM-enabled interorganizational collaboration capabilities (including information sharing capability and collaborative decision-making capability) as important factors determining the resultant performance gains from BIM implementation in construction projects. Considering the important roles of designers and general contractors in executing project design and construction activities, the model was empirically tested using two separate data sets collected from designers and general contractors in China to illustrate how these two types of participating organizations benefit differently from project BIM implementation activities. The remainder of this paper proceeds as follows. The next section draws upon resource dependence theory to develop the research model and propose the research hypotheses on the impacts of BIM implementation. Section 3 outlines the data and measurements used to test the model and hypotheses. This is followed by the presentation of quantitative data analysis results based on the qartial least squares (PLS) technique and the bootstrapping mediation approach in Section 4. Section 5 discusses the findings and Section 6 concludes this paper.

\section{Research model and hypotheses}

\author{
2.1 Research model of performance impacts of BIM \\ implementation
}

As a theoretical perspective building on the early works in social exchange theory (Emerson, 1962), resource dependence theory has become one of the most influential theories in organizational studies as a result of its full exposition by Pfeffer and Salancik (1978). The basic assumptions of resource dependence theory are that few organizations are internally self-sufficient with respect to strategically important resources, and that this lack of selfsufficiency will create potential dependence on other related organizations as well as introduce uncertainty into organizational processes (Pfeffer, 1982). Based on these assumptions, resource dependence theory proposes that organizations need to manage dependence and reduce uncertainty by purposely structuring their exchange relationships with other organizations by means of establishing formal and semiformal interorganizational links (Pfeffer and Salancik, 1978). For the present study, the implications of resource dependence theory not only include its accentuation of the importance of interorganizational links in improving organizational performance, but also the identification of resource dependence as the key antecedent motivating the establishment of interorganizational links.

In temporary coalitions like construction projects which involve a variety of organizations from different disciplines collaborating to accomplish ad hoc and poorly structured tasks, participating organizations are particularly dependent on each other for related resources required for effective functioning (Winch, 2010). These resources include both physical ones such as equipments and nonphysical ones such as proprietary information and disciplinary expertise. Limited by the representation methods of project life-cycle data, however, such interdependence in construction projects is generally underemphasized by traditional project management practices, and the established interorganizational collaboration links between project participants are often ineffective to manage the interorganizational dependence and reduce the resultant uncertainty in design and construction processes (Froese, 2010). As an innovative technology to parametrically create and visually represent project lifecycle data, BIM could not only provide greater visibility into the underlying resource exchange requirements of involved project participating organizations (Froese, 2010), but also facilitate a more structured interorganizational collaboration process to support better exchange and co-utilization of resources including proprietary information and disciplinary expertise (Eastman et al., 2011). From the perspective of resource dependence theory, therefore, BIM could be viewed as a boundary spanning tool for project participants to enhance interorganizational 
collaboration capabilities and manage interorganizational dependence related to proprietary information and disciplinary expertise. As resource dependence theory underlines the criticality of establishing interorganizational links for organizations to ensure resource availability, this paper focuses on examining the roles of BIM-enabled interorganizational collaboration capabilities, including information sharing capability and collaborative decisionmaking capability, in realizing performance gains from BIM implementation in construction projects.

With regard to the measurement of performance gains from BIM implementation, recent investigations have attempted to use objective project data to quantitatively measure related gains such as reduced change orders, increased labor productivity and accelerated project schedule (Cao et al., 2015; Barlish and Sullivan, 2012; Francom and El Asmar, 2015; Giel and Issa, 2013; Lu et al., 2014; Poirier et al., 2015; Sacks and Barak, 2008). While indicating that BIM implementation could not only improve the effectiveness of project tasks but also enhance the efficiency of design and construction activities, these investigations also suggest that many of the performance gains from BIM implementation are relatively qualitative and thus difficult to measure using objective data (Barlish and Sullivan, 2012; Giel and Issa, 2013; Lu et al., 2014). Even for such quantitative gains as reduced change orders, the related quantification process is still quite complex and challenging, as a large amount of data needs to be accurately recorded and highly similar projects without BIM use need to be available for necessary cross-project comparisons (Barlish and Sullivan, 2012; Giel and Issa, 2013). While recent academic literature has increasingly claimed the difficulty and limitation of using objective data to measure BIM implementation benefits (Cao et al., 2015; Lu et al., 2014; Won and Lee, 2016), some industry reports such as the SmartMarket Report series have also more frequently employed perceived returns on investment (ROI) rather than objective data to assess performance impacts of BIM implementation (Bernstein, 2015; Lee et al., 2012). To structurally compare the performance gains from BIM implementation in different projects and draw conclusions on how they are associated with BIM implementation characteristics and BIM-enabled interorganizational collaboration capabilities, this study also uses two perceptual constructs of performance gains which are adapted from information systems literature in other industries (Gattiker and Goodhue, 2005): BIM-enabled task efficiency improvement, and BIM-enabled task effectiveness improvement.

On the basis of these considerations, the research model examining the performance impacts of project BIM implementation on design and construction performance is outlined in Fig. 1. The principal relationships hypothesized in the model are those among the extent of BIM implementation, BIM-enabled interorganizational collaboration capabilities, and BIM-enabled performance gains. Specifically, the research model analyzes the variables of interorganizational collaboration capabilities and performance gains at the level of project participating organizations (i.e., designers and general contractors), and the extent of BIM implementation is analyzed as a contextual factor at the project level.

\subsection{Impacts of BIM implementation on interorganizational collaboration capabilities}

As a core concept related to the research model, collaboration refers to "a process through which parties with diverse interests and interdependent resources interact to search for solutions to problems that go beyond their own limited vision of what is possible" (Yan and Dooley, 2014). Extant literature has examined the concept from different perspectives but widely conceived information sharing and collaborative decision-making as two key elements of collaboration in an interorganizational context (Cao and Zhang, 2011; Sahin and Robinson, 2005). While information sharing could be described as the "heart" (Lamming, 1996), "lifeblood" (Ian Stuart and

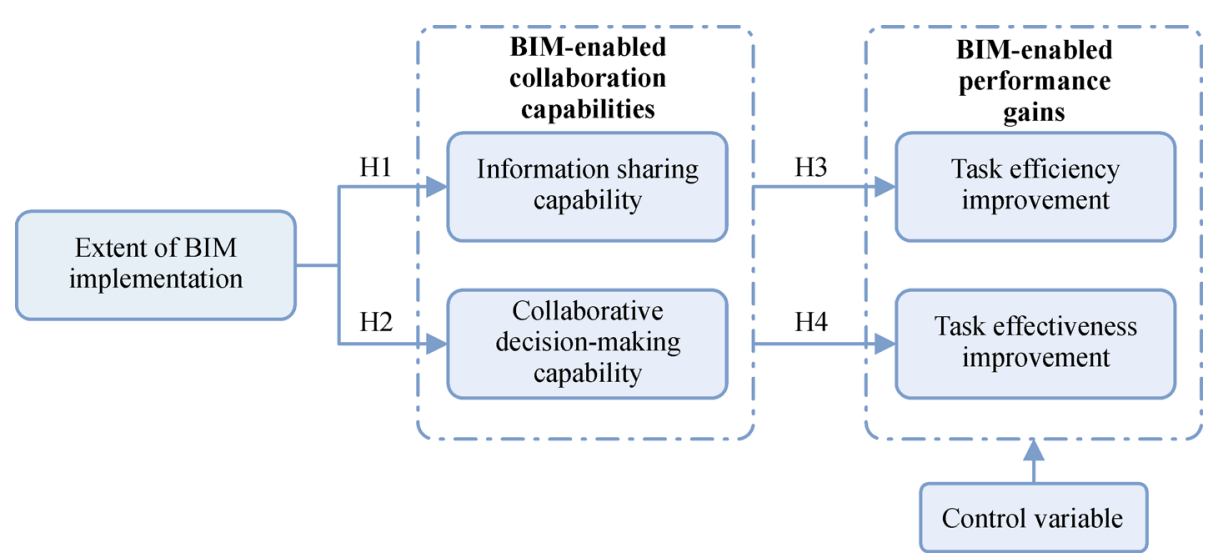

Fig. 1 Research model 
McCutcheon, 1996) and "nerve center" (Chopra and Meindl, 2001) of interorganizational collaboration, collaborative decision-making is a more externally visible element which is directly related to the value creation of collaboration processes. As a construct to reflect the state of the collaboration between interdependent organizations (Allred et al., 2011; Rai et al., 2006), interorganizational collaboration capability also comprises both information sharing capability and collaborative decision-making capability. Within the interorganizational contexts of construction projects examined in this study, specifically, information sharing capability is used to reflect the extent to which a focal organization (e.g., designers and general contractors) has realized the exchange of proprietary information with its partners in a timely, complete, accurate and consistent manner (Cao and Zhang, 2011), while collaborative decision-making capability is used to reflect the extent to which a focal organization has realized the collaboration with its partners to jointly formulate planning and operation decisions optimizing the benefits of all related parties (Wong et al., 2015). From the perspective of resource dependence theory, these two types of capabilities not only directly relate to the synergy of the non-physical resources of proprietary information and disciplinary expertise, but could also facilitate more efficient and effective interorganizational exchange of related physical resources. As an innovative technology of an integrated nature, BIM could be used to improve both of these capabilities of related participants in construction projects.

A basic characteristic of BIM is that the technology uses parametric objects to model the information of facility components and their design, construction and operation activities (Succar, 2009). Compared with traditional 2D information representation methods, such an object-based modeling method could not only enable a more comprehensive and accurate creation of facility life-cycle data, but could also facilitate the created data to be exchanged more consistently among project participants throughout the facility life-cycle (Eastman et al., 2011). Moreover, a comprehensive implementation of BIM in construction projects is not limited to the isolated use of modeling software such as Revit and Tekla to create parametric models, but also involves the integrated use of modeling software with project information management platforms (e.g., Bentley Projectwise) and on-site sensing technologies (e.g., RFID) to realize more automatic updates and faster exchange of information within the created BIM models (Cao et al., 2014, 2015; Ding et al., 2014; Eastman et al., 2011). As such, BIM implementation activities could not only enhance the capability of project participants to share more complete, accurate and consistent information, but also improve the currency of the shared information.

Apart from supporting the creation and sharing of object-based information, BIM can also be implemented in a variety of extended areas including model-based visualization (e.g., 4D presentation of construction solutions), model-based analysis (e.g., model-based cost estimation) and model-based project monitoring and control (e.g., model-based on-site safety and quality control) (Cao et al., 2014, 2015). The implementation of BIM in these areas could enable more visual and accurate communications among project participants on related project problems and possible solutions, and provide technical support for the decision-making on project design schemes and construction plans. As such, BIM as a boundary spanning tool also has the potential to improve the collaborative decision-making capability of project participants.

Due to the variety of the implementation areas of BIM in a project life-cycle (Cao et al., 2015; Eastman et al., 2011; Hartmann et al., 2008), how BIM implementation activities improve the interorganizational collaboration capabilities of project participants would not be simply determined by whether BIM is adopted in a project, but largely impacted by the extent to which BIM is implemented in design and construction processes by project participants. These arguments lead to the following set of hypotheses.

H1. The extent of BIM implementation in a construction project is positively associated with the BIM-enabled information sharing capability of project participants.

$\mathrm{H} 2$. The extent of BIM implementation in a construction project is positively associated with the BIM-enabled collaborative decision-making capability of project participants.

2.3 Impacts of interorganizational collaboration capabilities on performance gains

According to resource dependence theory, organizations need to purposely structure their relationships with other organizations to obtain critical resources and thus achieve desired organizational outcomes (Pfeffer and Salancik, 1978). In the context of a construction project, the two types of BIM-enabled interorganizational collaboration capabilities not only directly relate to the integration of the non-physical resources of proprietary information and expertise, but could also facilitate a more efficient and effective synergy of related physical resources. Considering the substantial interdependence among project participants for the exchange of such resources, this study proposes that the two types of BIM-enabled interorganizational collaboration capabilities could further result in substantial performance gains for project participants, including improvements both in task efficiency and in task effectiveness. Specifically, task efficiency is conceptualized as the extent to which a task is completed in the required time frame with the allocated labor resources (Gattiker and Goodhue, 2005). Task effectiveness is 
conceptualized as the extent to which a task is completed with high-quality outcomes that satisfactorily fulfill the client/owner's needs (Hoegl and Gemuenden, 2001).

BIM-enabled interorganizational collaboration capabilities could be associated with higher task efficiency of project participants in several ways. If project participants can satisfactorily exchange their required information and collaboratively make critical decisions, they will spend less time in a variety of non-value-adding activities such as waiting for the most recent design information, and waiting for the verification of revised construction plans. BIMenabled high-quality information sharing and collaborative decision-making could also improve the efficiency of project value-adding activities through enabling faster analysis and communication on emergent project problems, supporting more rapid evaluation on design or construction solutions, and facilitating more off-site prefabrication of facility components. The above discussions lead to the following set of hypotheses.

H3a. Project participants with greater BIM-enabled information sharing capability are more likely to achieve a greater extent of task efficiency improvement.

H3b. Project participants with greater BIM-enabled collaborative decision-making capability are more likely to achieve a greater extent of task efficiency improvement.

An important aspect of the impacts of BIM-enabled interorganizational collaboration capabilities on project task effectiveness is the reduction of design errors and construction rework. Together with other performance problems such as cost overruns and schedule slippages, design errors and resultant construction rework have been relatively common in project execution practices (Lopez and Love, 2012). Similar to the formation of other project performance problems, the generation of design errors and construction rework is often related to collaboration problems such as inaccurate exchange of design and construction intention, non-timely communication of project information, and lack of related parties' participation during project decision-making. As such, BIMenabled information sharing and collaborative decisionmaking will naturally facilitate the reduction of design errors and construction rework. Apart from reducing errors and rework, the value of BIM-enabled information sharing and collaborative decision-making could be further reflected in integrating information and expertise resources from different project participants to obtain design and construction solutions that have lower construction and operation costs, possess higher environmental performance, and more satisfactorily fulfill the needs of project clients/owners. These considerations lead to the following set of hypotheses.

H4a. Project participants with greater BIM-enabled information sharing capability are more likely to achieve a greater extent of task effectiveness improvement.

H4b. Project participants with greater BIM-enabled collaborative decision-making capability are more likely to achieve a greater extent of task effectiveness improvement.

\section{Measurements and data}

\subsection{Measurement development}

This study used a questionnaire survey as the method of collecting data to test the hypotheses. The measurement items in the questionnaire were initially developed based on information gleaned from the relevant literature, and a pre-test involving 53 respondents (34 from designers and 19 from general contractors) in BIM-based construction projects was then conducted via an online survey system (www.sojump.com) to identify ambiguous expressions and preliminarily test the validity of related constructs. Apart from project characteristic variables such as project size, a total of five variables related to this study were measured in the questionnaire: extent of BIM implementation (EB), BIM-enabled information sharing capability (ISC), BIMenabled collaborative decision-making capability (CDC), BIM-enabled task efficiency improvement (TEY), and BIM-enabled task effectiveness improvement (TES). The variable of $\mathrm{EB}$ was measured using an aggregated index on BIM usage in a total of 13 implementation areas in design and construction stages identified by Cao et al. (2014). The extent of BIM implementation in each area was measured on a three-point scale of " 0 " (not used), " 1 " (some use) and " 2 " (extensive use). With the aim of improving the comprehensiveness of the implementation measurement, this study followed similar studies on other technologies (e.g., Zhu et al., 2006) to perform a principal component analysis (PCA) to aggregate the BIM implementation in the 13 examined areas into one summated factor, and used the factor scores to gauge the extent of BIM implementation in different projects.

In contrast to EB, the variables of ISC, CDC, TEY and TES were all modeled as reflective constructs with sevenpoint scale items ("1" = strongly disagree; "7" = strongly agree). The measurement items of these variables are shown in Table 1. The items of ISC were adapted from Cao and Zhang (2011), and a total of four items were adopted to measure the extent to which a focal project participating organization has been enabled to sharing information with other related participating organizations in a timely, complete, accurate and consistent manner based on BIM models. The operationalization of CDC was partly based on the studies of Wong et al. (2015) and Cao and Zhang (2011) in other industries, and the measurement items were largely revised to suit the context of BIM implementation in construction projects. A total of four items were ultimately adopted to reflect the extent to which a focal project participating organization has been enabled to regularly collaborate with other related participating 
organizations to jointly formulate design/construction plans, jointly select design/construction solutions, jointly adjust and optimize design/construction solutions, and jointly solve emergent design/construction problems based on BIM models. The items of TEY were adapted from Gattiker and Goodhue (2005) and were reworded to better reflect the impacts of BIM implementation in the context of construction projects. The operationalization of TES was based on Hoegl and Gemuenden's (2001) study on teamwork effectiveness and Gao and Fischer's (2008) study on BIM implementation benefits. Three items were ultimately adopted to reflect the extent to which BIM implementation has helped a focal project participating organization to reduce design errors or construction rework, explore design/construction solutions with higher quality and less cost, and accomplish design/construction products that more satisfactorily fulfill the client/owner's needs. The items of TEY and TES have both been previously validated by $\mathrm{Cao}$ et al. (2015). While EB was measured as a contextual factor at the project level, ISC, CDC, TEY and TES were all measured at the level of a specific project participating organization (i.e., the design or construction team in which the respondent was employed). As a control variable used to check possible influences of project characteristics on the performance gains from BIM implementation (Bryde et al., 2013), project size was measured by project investment value.

\subsection{Sampling and data collection}

This study only considered those well-informed senior and professional individuals directly involved in project BIM implementation activities on the Chinese mainland as targeted respondents for the survey. Constrained by the still limited development of BIM in China, this study failed to use a completely random sampling method to elicit BIMbased projects and related project respondents from a specific project database. Instead, respondents from designers and general contractors in diversified types of BIM-based projects were identified through a mix of methods, including contacting related industry professionals participating in BIM forums, interviewing pioneering corporations in BIM utilization, and obtaining information from online BIM communication communities. The identified respondents were then invited to complete the survey questionnaire based on their most recent BIM-based project which had already been completed or had already entered into the construction stage. It was anticipated that indicating the respondents to select their most recent project would not only enable them

Table 1 Measurement items

\begin{tabular}{|c|c|c|c|c|}
\hline \multirow{2}{*}{ Construct } & \multirow{2}{*}{ Code } & \multirow{2}{*}{ Items } & \multicolumn{2}{|c|}{ Factor loadings } \\
\hline & & & Designer & Contractor \\
\hline \multirow{4}{*}{$\begin{array}{l}\text { BIM-enabled } \\
\text { information } \\
\text { sharing capability } \\
\text { (ISC) }\end{array}$} & ISC1 & $\begin{array}{l}\text { Based on BIM models, our team has been enabled to share information with other } \\
\text { related participants in a timely manner }\end{array}$ & 0.916 & 0.890 \\
\hline & ISC2 & $\begin{array}{l}\text { Based on BIM models, our team has been enabled to share information with other } \\
\text { related participants in a complete manner }\end{array}$ & 0.933 & 0.926 \\
\hline & ISC3 & $\begin{array}{l}\text { Based on BIM models, our team has been enabled to share information with other } \\
\text { related participants in an accurate manner }\end{array}$ & 0.943 & 0.920 \\
\hline & ISC4 & $\begin{array}{l}\text { Based on BIM models, our team has been enabled to share information with other } \\
\text { related participants in a consistent manner }\end{array}$ & 0.844 & 0.857 \\
\hline \multirow{4}{*}{$\begin{array}{l}\text { BIM-enabled } \\
\text { collaborative } \\
\text { decision-making } \\
\text { capability (CDC) }\end{array}$} & $\mathrm{CDC} 1$ & $\begin{array}{l}\text { Based on BIM models, our team has been enabled to regularly collaborate with other } \\
\text { related participants to jointly formulate design/construction plans }\end{array}$ & 0.857 & 0.897 \\
\hline & $\mathrm{CDC} 2$ & $\begin{array}{l}\text { Based on BIM models, our team has been enabled to regularly collaborate with other } \\
\text { related participants to jointly compare and select design/construction solutions }\end{array}$ & 0.906 & 0.916 \\
\hline & CDC3 & $\begin{array}{l}\text { Based on BIM models, our team has been enabled to regularly collaborate with other } \\
\text { related participants to jointly adjust and optimize design/construction solutions }\end{array}$ & 0.870 & 0.933 \\
\hline & CDC4 & $\begin{array}{l}\text { Based on BIM models, our team has been enabled to regularly collaborate with other } \\
\text { related participants to jointly solve emergent design/construction problems }\end{array}$ & 0.911 & 0.875 \\
\hline \multirow{3}{*}{$\begin{array}{l}\text { BIM-enabled task } \\
\text { efficiency } \\
\text { improvement } \\
\text { (TEY) }\end{array}$} & TEY1 & BIM implementation has enabled a faster execution of our team's design/construction activities & 0.898 & 0.927 \\
\hline & TEY2 & $\begin{array}{l}\text { BIM implementation has increased our team's productivity in related design and } \\
\text { construction processes }\end{array}$ & 0.941 & 0.946 \\
\hline & TEY3 & BIM implementation has saved time for our team to conduct related design/construction activities & 0.945 & 0.887 \\
\hline \multirow{3}{*}{$\begin{array}{l}\text { BIM-enabled task } \\
\text { effectiveness } \\
\text { improvement } \\
\text { (TES) }\end{array}$} & TES1 & BIM implementation has reduced errors and rework in our team's design/construction activities & 0.850 & 0.813 \\
\hline & TES2 & $\begin{array}{l}\text { BIM implementation has helped our team to explore better design/construction solutions } \\
\text { with higher quality and less cost }\end{array}$ & 0.884 & 0.897 \\
\hline & TES3 & $\begin{array}{l}\text { BIM implementation has enabled our team's design/construction outcomes to more } \\
\text { satisfactorily fulfill the client/owner's needs }\end{array}$ & 0.901 & 0.867 \\
\hline
\end{tabular}


to recollect the information on the project BIM implementation activities and performance, but also help minimize possible response biases as many respondents may have a tendency to choose their most successful BIMbased construction projects.

Responses were collected from the respondents by means of e-mail, personal visits and an online survey system from December 2014 to February 2015. About 570 respondents were contacted through network-based channels (including emails and WeChat) and were informed that they could choose to participate in the survey whether through directly responding to the e-mail or through logging into an online survey system (www.sojump.com). Based on the network-based contacts, 23 responses were collected through email and 247 responses through the online survey system. As for the method of personal visits, about 85 respondents were contacted and 56 responses were collected. After the omission of responses containing incomplete or potentially unreliable information, a total of 251 valid responses were ultimately included in subsequent analyses. Among the 251 valid responses, 136 were from project designers and 115 were from general contractors. Demographic characteristics of the samples corresponding to the valid responses are shown in Table 2. It is evident that the surveyed BIM-based projects are diverse in terms of project size, project type and project nature. It is also evident, however, that most of the project respondents are from the regions of East China, South Central China and North China, indicating that there is also a probable non-balanced distribution of the locations of the surveyed projects. Apart from being caused by the sampling problem, such a non-balanced distribution could also be largely attributed to the non-balanced development of BIM in different regions in China at present.

After the omission of invalid responses, most respondents in the samples are senior or professional individuals with knowledge of BIM implementation in the surveyed projects. In the designer sample, $11.03 \%$ of the respondents are project managers or chief project engineers, $21.32 \%$ are BIM managers, $58.82 \%$ are BIM engineers, the remaining $8.82 \%$ being other types of engineers also directly involved in the implementation of BIM. In the general contractor sample, the percentages of the four types of project respondents are $25.22 \%, 18.26 \%, 48.70 \%$ and $7.83 \%$ respectively. To quantitatively examine whether the survey responses were biased due to the positions of the respondents, both the designer and general contractor samples were split into two groups: the group of BIM managers/BIM engineers, and the group of project managers/non-BIM engineers. Independent sample $t$-tests were then implemented to assess the differences in the

Table 2 Demographic information

\begin{tabular}{|c|c|c|c|c|c|}
\hline \multirow{2}{*}{ Variable } & \multirow{2}{*}{ Category } & \multicolumn{2}{|c|}{ Designer sample } & \multicolumn{2}{|c|}{ General contractor sample } \\
\hline & & Number & Percentage & Number & Percentage \\
\hline \multirow{4}{*}{$\begin{array}{l}\text { Project } \\
\text { size }\end{array}$} & Below $¥ 50$ million & 37 & 27.21 & 20 & 17.39 \\
\hline & $¥ 50-200$ million & 46 & 33.82 & 36 & 31.30 \\
\hline & $¥ 200-1000$ million & 33 & 24.26 & 43 & 37.39 \\
\hline & Above $¥ 1000$ million & 20 & 14.71 & 16 & 13.91 \\
\hline \multirow{8}{*}{$\begin{array}{l}\text { Project } \\
\text { type }\end{array}$} & Residential & 28 & 20.59 & 18 & 15.65 \\
\hline & Commercial & 46 & 33.82 & 40 & 34.78 \\
\hline & Cultural & 6 & 4.41 & 13 & 11.30 \\
\hline & Sporting & 3 & 2.21 & 3 & 2.61 \\
\hline & Hospital & 3 & 2.21 & 7 & 6.09 \\
\hline & Transportation & 13 & 9.56 & 17 & 14.78 \\
\hline & Industrial & 20 & 14.71 & 9 & 7.83 \\
\hline & Others & 17 & 12.50 & 8 & 6.96 \\
\hline \multirow{2}{*}{$\begin{array}{l}\text { Project } \\
\text { nature }\end{array}$} & Public & 76 & 55.88 & 71 & 61.74 \\
\hline & Private & 60 & 44.12 & 44 & 38.26 \\
\hline \multirow[t]{6}{*}{ Location $^{\mathrm{a}}$} & North China & 16 & 11.76 & 13 & 11.30 \\
\hline & North-east China & 3 & 2.21 & 1 & 0.87 \\
\hline & East China & 61 & 44.85 & 67 & 58.26 \\
\hline & South Central China & 34 & 25.00 & 22 & 19.13 \\
\hline & South-west China & 14 & 10.29 & 5 & 4.35 \\
\hline & North-west China & 8 & 5.88 & 7 & 6.09 \\
\hline
\end{tabular}

Note: a Location of the respondent at the time of the survey, it might be different from the location of the surveyed project. 
means of the multi-scale variables between the two groups, and no statistically significant difference was found for the analyzed variables (the $p$-values of the $t$-tests for ISC, CDC, TEY and TES range from 0.266 to 0.583 for the designer sample, and from 0.535 to 0.885 for the general contractor sample).

\section{Data analyses and results}

This study used PLS, as implemented in the SmartPLS 2.0 M3 program, as the structural equation modeling (SEM) technique to validate the measurements and test the hypothesized relationships. Compared with covariancebased SEM techniques such as LISREL, PLS as a components-based technique is considered to be advantageous in analyzing research models with single-item constructs and processing data with non-normal distributions (Hair et al., 2012). As for the sample size requirement for using PLS, the most commonly cited rule is the " 10 times rule," which suggests that the sample size should be at least ten times the largest number of structural paths directed at a particular latent construct in the structural model (Hair et al., 2012). The latent constructs with the largest number of directed structural paths in the present study are the variables of TEY and TES (number of paths is 4 while the direct path from EB is included), and the sizes of the two samples both satisfactorily meet the "10 times rule." After using the PLS technique to assess the measurements and test the hypothesized relationships, this section will further quantitatively analyze the mediation effects of BIM-enabled interorganizational collaboration capabilities, and compare the data analysis results for the designer sample and general contractor sample.

\subsection{Measurement validation}

The validity of the measurements was assessed in terms of internal consistency, convergent validity and discriminant validity. Internal consistency was examined using the estimate of composite reliability. For the designer sample, as shown in Table 3, the composite reliability values of the examined constructs all exceed the threshold of 0.70
(Fornell and Larcker, 1981). To compare the status of project BIM implementation for the design and general contractor samples, the extent of BIM implementation was measured as a summated factor which was calculated through PCA analysis on the data of both samples $(N=$ 251). Therefore, its reliability and validity measures were not calculated in the PLS-based process. Further examination of the internal consistency of the summated factor in the program of SPSS Statistics 21.0 also yielded a satisfactory Cronbach's Alpha of 0.853. Convergent validity assesses the degree to which the items underlying a construct actually measure the same conceptual variable. The first evidence of convergent validity is provided by the values of average variance extracted (AVE). As shown in Table 3, each AVE is above the criterion of 0.5 , indicating that at least 50 percent of the variance in the items can be accounted for by their respective construct. Further evidence of convergent validity is obtained by estimating the factor loadings of the measurement items. The standardized factor loadings of the items on their respective constructs, as shown in Table 1, are all above the threshold of 0.7 and are significant at the $0.1 \%$ level. Discriminant validity examines the extent to which different constructs diverge from one another. It is evident that the square roots of the AVE (values on the diagonal of the correlation matrix in Table 3) are all larger than the absolute value of inter-construct correlations (off-diagonal values), suggesting that the measurements possess satisfactory discriminant validity. As shown in Table 1 and Table 4, corresponding indicators for the general contractor sample similarly suggest that the measurements have satisfactory internal consistency, convergent validity and discriminant validity.

\subsection{Hypothesis testing}

A bootstrapping procedure with 5000 resamples was performed to compute standard errors and thus test the statistical significance of the hypothesized relationships. The results of the bootstrap-based PLS analyses for the designer sample and the general contractor sample are both presented in Fig. 2. For the designer sample, the impact of BIM implementation extent on the two BIM-enabled

Table 3 Measurement validity and construct correlations: Designer sample

\begin{tabular}{|c|c|c|c|c|c|c|c|c|c|}
\hline \multirow{2}{*}{ Construct } & \multirow{2}{*}{ Mean } & \multirow{2}{*}{$\mathrm{SD}$} & \multirow{2}{*}{$\mathrm{CR}$} & \multirow{2}{*}{ AVE } & \multicolumn{5}{|c|}{ Correlation matrix ${ }^{\mathrm{b}}$} \\
\hline & & & & & EB & IIC & IDC & TEY & TES \\
\hline 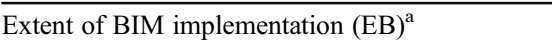 & -0.03 & 0.99 & na & na & na & & & & \\
\hline Information sharing capability (ISC) & 4.69 & 1.29 & 0.95 & 0.83 & 0.31 & 0.91 & & & \\
\hline Collaborative decision-making capability (CDC) & 4.85 & 1.05 & 0.94 & 0.79 & 0.32 & 0.49 & 0.89 & & \\
\hline Task efficiency improvement (TEY) & 4.36 & 1.43 & 0.95 & 0.86 & 0.33 & 0.29 & 0.34 & 0.93 & \\
\hline Task effectiveness improvement (TES) & 5.47 & 0.99 & 0.91 & 0.77 & 0.34 & 0.43 & 0.46 & 0.55 & 0.88 \\
\hline
\end{tabular}

Note: $\mathrm{SD}=$ standard deviation; $\mathrm{CR}=$ composite reliability; $\mathrm{AVE}=$ average variance extracted.

${ }^{\text {a }}$ Values are calculated based on PCA analysis, related measures are not applicable for this construct.

${ }^{\mathrm{b}}$ Bold values on the diagonal represent the square root of AVE. 
Table 4 Measurement validity and construct correlations: General contractor sample

\begin{tabular}{|c|c|c|c|c|c|c|c|c|c|}
\hline \multirow{2}{*}{ Construct } & \multirow{2}{*}{ Mean } & \multirow{2}{*}{$\mathrm{SD}$} & \multirow{2}{*}{$\mathrm{CR}$} & \multirow{2}{*}{ AVE } & \multicolumn{5}{|c|}{ Correlation matrix ${ }^{\mathrm{b}}$} \\
\hline & & & & & EB & IIC & IDC & TEY & TES \\
\hline 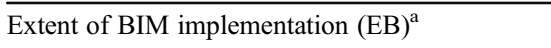 & 0.03 & 1.02 & na & na & na & & & & \\
\hline Information sharing capability (ISC) & 4.57 & 1.31 & 0.94 & 0.81 & 0.33 & 0.90 & & & \\
\hline Collaborative decision-making capability (CDC) & 4.96 & 1.15 & 0.95 & 0.82 & 0.33 & 0.44 & 0.91 & & \\
\hline Task efficiency improvement (TEY) & 5.23 & 1.10 & 0.94 & 0.85 & 0.32 & 0.34 & 0.37 & 0.92 & \\
\hline Task effectiveness improvement (TES) & 5.56 & 0.88 & 0.89 & 0.74 & 0.32 & 0.44 & 0.41 & 0.55 & 0.86 \\
\hline
\end{tabular}

Note: $\mathrm{SD}=$ standard deviation; $\mathrm{CR}=$ composite reliability; $\mathrm{AVE}=$ average variance extracted.

${ }^{a}$ Values are calculated based on PCA analysis, related measures are not applicable for this construct.

${ }^{\mathrm{b}}$ Bold values on the diagonal represent the square root of AVE.

interorganizational collaboration capabilities (i.e., ISC, $\mathrm{CDC})$ are both significant at the $0.1 \%$ level, thus Hypotheses 1 and 2 are supported. It is also shown that the paths between CDC and the two variables of performance gains (i.e., TEY and TES) are both statistically significant at the $0.1 \%$ or $5 \%$ level, hence Hypotheses $3 \mathrm{~b}$ and $4 \mathrm{~b}$ are also supported. With respect to ISC, the results show that the variable is significantly associated with TES at the $1 \%$ level but not significantly associated with TEY after controlling for the impact of project size. Therefore Hypothesis $4 \mathrm{a}$ is supported while Hypothesis 3a is not. A noteworthy result is that while CDC are significantly associated with both TEY and TES, the path coefficient for TES $(\beta=0.330, p<0.001)$ is larger than that for TEY $(\beta=0.248, p<0.05)$. These results collectively suggest that while designers' collaboration with other project participants to share high-quality information and jointly make decisions does have the potential to create substantial performance gains, its impact on design effectiveness is stronger than that on design efficiency. As for the control variable, project size is significantly associated with neither TEY nor TES while the impacts of ISC and CDC are considered.

For the general contractor sample, it is evident that the extent of BIM implementation is significantly associated with the two variables of BIM-enabled interorganizational collaboration capabilities (i.e., ISC and CDC) which are, in turn, both significantly associated with TEY and TES. Therefore, Hypotheses 1, 2, 3a, 3b, 4a, 4b are all supported by the data of the general contractor sample. As for the control variable, project size is again significantly associated with neither TEY nor TES while the impacts of ISC and CDC are considered.

4.3 Analysis of mediation effects of interorganizational collaboration capabilities

The mediation effects of ISC and CDC on the relationships between the extent of BIM implementation and the two variables of performance gains (i.e., TEY and TES) were further assessed using the bootstrapping approach (Preacher and Hayes, 2004). As a nonparametric resampling procedure to directly test the significance of mediation effects, the bootstrapping approach does not impose assumptions on the shape of the sampling distribution of the mediation effect statistic and has stronger statistical power than the traditional causal steps approach, especially for small sample size data (Preacher and Hayes, 2004). Besides these advantages, the ability of the bootstrapping approach to assess both the individual and collective mediation effects of multiple mediating variables (Preacher and Hayes, 2008) further makes it particularly appropriate as the analysis technique for this study. The analysis of the mediation effects was performed

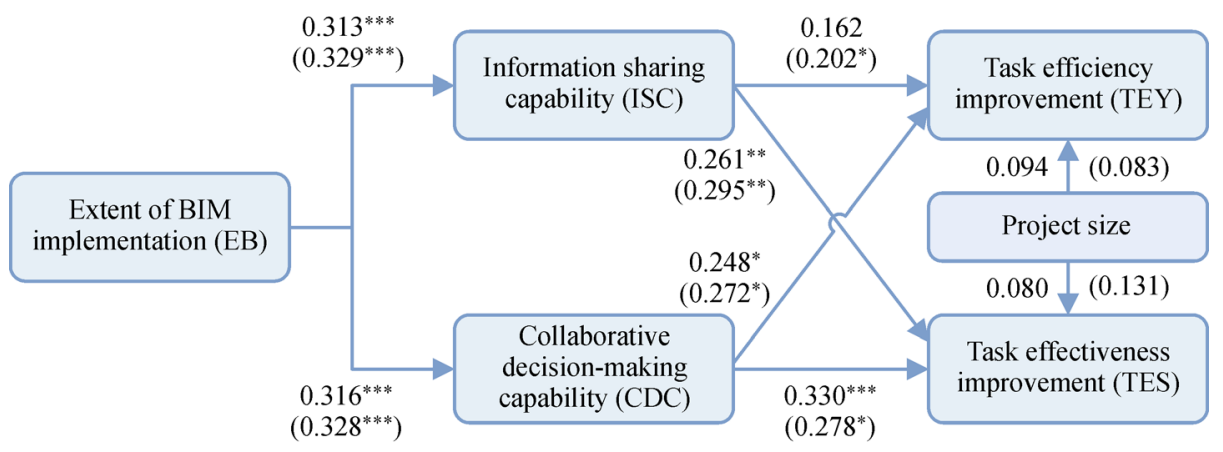

Significance level: ${ }^{*} p<0.05 ;{ }^{* *} p<0.01 ;{ }^{* * *} p<0.001$. Values outside parentheses are the results for the designer sample and values inside are the results for the general contractor sample.

Fig. 2 Results of PLS analyses for the research model 
using the SPSS macro developed by Preacher and Hayes (2008), and the analysis results are shown in Table 5.

The bias-corrected (BC) bootstrap confidence intervals (CIs) in Table 5 show that all the examined mediation effects of ISC and CDC on the impacts of EB on TEY and TES for the two samples are significant at the 5\% level with three exceptions: the mediation effects of ISC and CDC on the relationship between EB and TEY for the designer sample, and the mediation effect of ISC on the relationship between EB and TEY for the general contractor sample. Although three of the eight individual mediation effects of ISC and CDC are found to be nonsignificant, the bootstrapping results further reveal that the collective mediation effects of the two capability variables on the relationships between EB and the two variables of performance gains (i.e., TEY and TES) are all significant for both samples. These results provide strong evidence regarding the important role of BIM-enabled interorganizational collaboration capabilities in determining performance gains for project participants.

To better understand the mediation effects of the BIMenabled interorganizational collaboration capabilities, the direct links from EB to the two variables of performance gains (i.e., TEY and TES) were further added in the research model, and the PLS analysis results showed that all these direct links are significant at the $5 \%$ level for both the designer and general contractor samples with only one exception: the direct link from EB to TES for the general contractor sample $(\beta=0.127, p>0.05)$. Taken together, these results indicate that apart from improving inter- organizational collaboration capabilities of project participants, the implementation of BIM may also enhance the efficiency and effectiveness of project activities through other channels, such as improving intra-organizational collaboration capabilities of project participating organizations and generating automational effects.

4.4 Comparison of benefits for designers and general contractors

To identify how related participating organizations benefit differently from project BIM implementation activities, this study further compared the data analysis results for the samples from designers and general contractors. As this study did not follow a dyadic sampling approach to collect data from matched pairs of designers and general contractors in the same projects, the projects reported by designers and general contractors do not strictly correspond to each other. Before comparing the analysis results of performance impacts for the two samples, therefore, it is necessary to first guarantee the equivalence between the two samples in project characteristics and project BIM implementation context which are both related to the performance gains of project participants. As project characteristic factors including project size, project type and project nature are all category variables, a series of $\chi^{2}$ tests were conducted to examine the between-sample differences. For the characteristic factor of project type, as the frequency of some categories (such as sporting and hospital categories) are relatively low and may impact the

Table 5 Mediation effects of BIM-enabled interorganizational collaboration capabilities

\begin{tabular}{|c|c|c|c|c|c|c|c|c|}
\hline \multicolumn{3}{|c|}{ Mediation path } & \multicolumn{3}{|c|}{ Designer sample } & \multicolumn{3}{|c|}{ General contractor sample } \\
\hline \multirow{2}{*}{ IV } & \multirow{2}{*}{ DV } & \multirow{2}{*}{ MV } & \multicolumn{2}{|c|}{$\mathrm{BC} 95 \% \mathrm{CI}$} & \multirow{2}{*}{ Significance } & \multicolumn{2}{|c|}{ BC 95\% CI } & \multirow{2}{*}{ Significance } \\
\hline & & & Lower & Upper & & Lower & Upper & \\
\hline \multirow[t]{3}{*}{ EB } & TEY & ISC & -0.022 & 0.121 & Non-significant & -0.001 & 0.142 & Non-significant \\
\hline & & $\mathrm{CDC}$ & -0.002 & 0.156 & Non-significant & 0.004 & 0.176 & Significant \\
\hline & & Total & 0.029 & 0.203 & Significant & 0.054 & 0.242 & Significant \\
\hline \multirow[t]{3}{*}{ EB } & TES & ISC & 0.014 & 0.170 & Significant & 0.031 & 0.189 & Significant \\
\hline & & $\mathrm{CDC}$ & 0.033 & 0.186 & Significant & 0.007 & 0.202 & Significant \\
\hline & & Total & 0.080 & 0.275 & Significant & 0.080 & 0.312 & Significant \\
\hline
\end{tabular}

Note: $\mathrm{IV}=$ Independent variable, $\mathrm{DV}=$ Dependent variable, $\mathrm{MV}=$ Mediating variable; The number of resample is 5000.

Table 6 Comparisons of construct values for designer and general contractor samples

\begin{tabular}{|c|c|c|c|c|c|c|c|c|}
\hline \multirow{2}{*}{ Variable } & \multicolumn{2}{|c|}{ Designer sample } & \multicolumn{2}{|c|}{ Contractor sample } & \multicolumn{4}{|c|}{ Independent sample $t$-test } \\
\hline & Mean & SD & Mean & SD & Difference & $t$-value & $p$-value & Sig. \\
\hline Extent of BIM implementation & -0.03 & 0.99 & 0.03 & 1.02 & -0.06 & -0.491 & 0.624 & No \\
\hline Information sharing capability & 4.69 & 1.29 & 4.57 & 1.31 & 0.12 & 0.725 & 0.469 & No \\
\hline Collaborative decision-making capability & 4.85 & 1.05 & 4.96 & 1.15 & -0.11 & -0.786 & 0.433 & No \\
\hline Task efficiency improvement & 4.36 & 1.43 & 5.23 & 1.10 & -0.87 & -5.461 & 0.000 & Yes \\
\hline Task effectiveness improvement & 5.47 & 0.99 & 5.56 & 0.88 & -0.10 & -0.814 & 0.416 & No \\
\hline
\end{tabular}


validity of $\chi^{2}$ test results, the eight categories of project type listed in Table 2 were combined into three categories: residential, commercial and others. The $\chi^{2}$ test results show that the differences between the designer and general contractor samples in project size, project type and project nature are all non-significant at the 5\% level ( $p$-values are $0.096,0.591$ and 0.348 respectively). With regard to the difference in project BIM implementation context, an independent sample $t$-test was performed to compare the mean values of EB for the two samples, and the result in Table 6 shows that the difference is non-significant at the $5 \%$ level. Based on these $\chi^{2}$ test and $t$-test results, the samples collected from designers and general contractors could be considered to be equivalent in terms of project characteristics and project BIM implementation context.

Based on the examination of the equivalence of the two samples in project characteristics as well as project BIM implementation context, this study also compared the between-sample differences in the values of ISC, CDC, TEY and TES using independent sample $t$-tests. As these capability and benefit variables were all measured at the level of project participating organizations (i.e., designer or generational contractor), the differences in the values of these variables between the two samples directly reflect how designers and general contractors differ in their BIMenabled interorganizational collaboration capabilities and BIM-enabled performance gains. From the $t$-test results shown in Table 6 , it is evident that the differences in the mean values of ISC $(t=0.725, p=0.469), \operatorname{CDC}(t=$ $-0.786, p=0.433)$ and TES $(t=-0.814, p=0.416)$ are all non-significant, but the mean value of TEY for the general contractor sample is significantly higher than that for the designer sample $(t=-5.461, p<0.001)$. A paired-samples $t$-test further reveals that the mean of TEY, which is relatively close to the neutral of " 4 " for a seven-point scale, is also significantly lower than that of TES for the designer sample $(t=-10.599, p<0.001)$. These results provide evidence that current BIM-enabled performance gains for designers have been primarily related to the enhancement of task effectiveness, and that the gains related to the improvement of task efficiency for designers have been much less substantial than those for general contractors.

With regard to the relationships among the examined variables, it is evident from Fig. 2 and Table 5 that the hypothesis testing results and the mediation analysis results are quite similar between the two samples. Specifically, most of the hypothesized relationships among EB, ISC, CDC, TEY and TES are supported by data from both samples, and the collective mediation effects of ISC and CDC on the relationships between EB and the two performance gain variables (i.e., TEY and TES) are found to be significant for both samples. These results provide strong evidence regarding the important role of BIM-enabled interorganizational collaboration capabilities in generating performance gains for both designers and general contractors. Accompanying these similarities, a distinct difference in the results for the two samples is that the association between ISC and TEY is significant at the $5 \%$ level for the general contractor sample but non-significant for the designer sample. This result provides evidence that BIM-enabled interorganizational collaboration in sharing high-quality information does not necessarily equivalently benefit related collaborating parties in terms of improving the efficiency of both design and construction activities. Further comparisons of the hypothesis testing and mediation analysis results also suggest that while designers' collaboration with other project participants to share high-quality information and jointly make decisions does have the potential to create substantial performance gains, its impact on design effectiveness is considerably stronger than that on design efficiency.

\section{Discussions, implications and future research}

\subsection{Discussions and implications}

The primary objective of this study is to use resource dependence theory as a lens to understand how BIM implementation activities impact the performance of different participating organizations in construction projects. Most of the hypothesized relationships are supported by the data from both designers and general contractors, and BIM-enabled interorganizational collaboration capabilities as a whole are found to significantly mediate the relationships between the extent of project BIM implementation and BIM-enabled performance gains for both designers and general contractors. These results validate the perspective of resource dependence theory in the context of construction projects, and provide evidence for the important boundary spanning role of BIM in assisting project participants to manage interorganizational dependence and improve organizational design/construction performance.

In fact, the interdependence among project participants is not a new claim in the construction industry, and the establishment of related coordination mechanisms to manage the interorganizational dependence has been rather common in construction project management practices (Shen and Chang, 2011). Limited by the 2D representation methods of project life-cycle data, however, traditional project management practices have largely focused on managing visible interorganizational dependence for physical resources, but under-emphasized the underlying interdependence for non-physical resources such as proprietary information and disciplinary expertise (Froese, 2010). As a result, critical information is often shared among project participants neither promptly nor consis- 
tently, and project design and construction solutions are often formulated by part of the related participants and then "thrown over the wall" to other participants. As an innovative technology to parametrically and visually represent project life-cycle data, BIM could not only provide greater visibility into the underlying resource dependence among project participating organizations, but also facilitate a more structured interorganizational collaboration process to support the integration of non-physical resources including proprietary information and disciplinary expertise and, therefore, to further facilitate the synergy of related physical resources. As such, the value of BIM is naturally related to the technology's response to the collaboration requirements resulting from the resource dependence among project participants, and BIM-enabled interorganizational collaboration capabilities naturally play important roles in determining resultant project benefits.

While providing evidence for the important roles of BIM-enabled interorganizational collaboration capabilities in determining performance gains for project participants, the results further suggest that there is a significant nonequivalence of the BIM implementation benefits for designers and general contractors. In details, the results reveal that BIM-enabled task efficiency improvement for designers is significantly less substantial than that for general contractors, and the resultant BIM implementation benefits for designers have been primarily related to the enhancement of task effectiveness. This non-equivalence could be partly attributed to the different roles played by BIM in design and construction processes. During construction processes, BIM is mainly used to guide the planning and execution of construction activities and, therefore, primarily acts as a supportive tool. During design processes, however, the integrated use of BIM requires designers to abandon the traditional $2 \mathrm{D}$ design paradigm and to conduct design activities based on fundamentally new design platforms and processes. Compared with construction processes, therefore, design processes will undergo more fundamental adjustments after the introduction of BIM technology. Due to the complexity of BIM-based design software, such adjustments will involve relatively long learning curves and thus do not necessarily lead to higher efficiency of design activities during early technology adoption periods.

The non-equivalence in the improvement of task efficiency for designers and general contractors also closely relates to the difference in the impacts of BIMenabled interorganizational collaboration on design and construction activities, as the data analysis results further reveal that the association between BIM-enabled information sharing capability and task efficiency improvement is more substantial for the general contractor sample than for the designer sample. From the resource dependence theory perspective, the difference in the impacts of BIM-enabled information sharing capability on design and construction efficiency is closely related to the different roles played by designers and general contractors in BIM-enabled interorganizational resource exchange processes. Due to the ability of BIM to increase the visibility of project data and support the automatic detailing of construction-level building models, specifically, a collaborative BIM implementation process generally requires designers to assume more responsibilities of construction detailing and to provide design models with more detailed information to other project participants including general contractors (Eastman et al., 2011). Therefore, collaborative BIM implementation activities will increase the responsibilities of designers as model-based information providers, and strengthen the dependence of other project participants (e.g., general contractors) on the information provided. Although designers are also dependent on other participating organizations' related information and could also gain efficiency-related benefits from BIM-based information sharing processes, such benefits may be offset by the increase of model detailing workloads and thus lead to the non-significant association between BIM-enabled information sharing capability and BIM-enabled task efficiency improvement. With regard to BIM-enabled collaborative decision-making capability, the variable is found to be significantly associated with the performance gains for designers, especially in the aspect of task effectiveness improvement. This result provides evidence that designers are particularly dependent on the expertise of other participating organizations to ensure the effectiveness of design activities and, therefore, underlines the importance of integrating the expertise from different disciplines during the early design stage in a project lifecycle.

With its attempt to unveil how project BIM implementation impacts the performance of different project participating organizations, this study has several managerial implications. As the empirical results provide evidence that BIM-enabled interorganizational collaboration capabilities as a whole play an important role in determining the impacts of BIM implementation on the efficiency and effectiveness of project activities, during project BIM implementation processes it is important for project participants to purposefully manage the extent to which BIM improves the quality of interorganizational information sharing and collaborative decision-making in order to maximize the potential benefits from BIM implementation. While providing evidence for the important role of BIMenabled interorganizational collaboration capabilities in project BIM implementation processes, the results further reveal that designers and general contractors benefit from collaborative BIM implementation activities significantly non-equivalently, which could also help further explain the wide existence of collaborative intention problems in project BIM implementation (Cao et al., 2015; Dossick and Neff, 2010) from the perspective of distributive equity (Scheer et al., 2003). As such, in order to improve the 
fairness of "pie-sharing" among project participants and thereby to incentivize their collaborative "pie-expansion" efforts during project BIM implementation, it is important for project clients/owners to appropriately offset the naturally formed non-equivalence of BIM implementation benefits while designing the contractual risk/reward terms for designers and general contractors.

\subsection{Limitations and future research directions}

The results of this study need to be interpreted in light of the following limitations. First, considering the potential impact of the number of analyzed variables on the stability of model analysis results given the limited sample sizes, this study only develops a parsimonious model to examine how BIM implementation activities impact the efficiency and effectiveness of project activities through improving the interorganizational collaboration capabilities of project participants, and have omitted related cultural and organizational factors which may substantially impact the BIM-enabled interorganizational collaboration process and resultant BIM implementation benefits. As a result, the amounts of some variables' variances explained by the research model are not at high levels (e.g., the $R^{2}$ values of ISC and CDC for the general contractor sample are only 0.109 and 0.108 respectively), which also provides evidence that BIM as a technological tool alone is not sufficient to automatically address all of the collaboration problems in construction projects. Combining resource dependence theory with other related theoretical perspectives, future research could attempt to incorporate relevant cultural and organizational factors in the research model and, therefore, provide a more comprehensive understanding of how varied performance impacts of BIM implementation are concretely generated across projects.

Second, the data used in this study were all self-reported data collected through a questionnaire survey. Although the use of this data collection method is necessary to conduct quantitative analyses and has been relatively common in empirical studies examining technology implementation benefits in other industries (e.g., Gattiker and Goodhue, 2005; Karimi et al., 2007), the collected data may be subject to the problem of common method biases (Podsakoff and Organ, 1986). As a statistical control technique, Harman's one-factor test on the five core constructs with perceptual measures (i.e., EB, ISC, CDC, TEY and TES) showed that no single dominant factor emerged and the largest factor only explained $30.64 \%$ and $30.39 \%$ of the total variances for the two samples, suggesting that common method biases are unlikely to be a serious threat to the findings of this study (Podsakoff and Organ, 1986). To further control the impact of potential response biases, however, future research could attempt to comprehensively use the methods of questionnaire survey and document analysis to collect multi-source data and cross-validate the data used for quantitative analysis.

\section{Conclusions}

Drawing on resource dependence theory, this paper developed a model to assess how the implementation of BIM in construction projects impacts the performance of project participants through improving their interorganizational collaboration capabilities. To probe deeper into whether and how individual participating organizations benefit differently from BIM implementation, the model was tested using two separate sets of survey data collected from designers and general contractors involved in BIMbased construction projects in China. Data analysis results based on the PLS technique and the bootstrapping mediation approach reveal that BIM-enabled capabilities of information sharing and collaborative decision-making as a whole play an important role in impacting the BIMenabled performance gains (including the improvements in task efficiency and task effectiveness) for both designers and general contractors. These results validate the perspective of resource dependence theory in the context of construction projects, and provide evidence for the important boundary spanning role of BIM in assisting project participants to manage interorganizational dependence and thus improve project performance. Further comparison of the data sets reveals that designers and general contractors benefit from project BIM implementation activities significantly non-equivalently, with BIMenabled task efficiency improvement for designers being significantly less substantial than that for general contractors, and the benefits for designers being primarily limited to the enhancement of task effectiveness. From the resource dependence theory perspective, this non-equivalence is closely related to the different roles played by designers and general contractors within BIM-enabled interorganizational resource exchange processes. This study contributes to the growing BIM literature not only by elucidating the pathways through which the implementation of BIM improves the performance of related participating organizations in construction projects, but also by characterizing how and why different project participating organizations benefit differently from collaborative BIM implementation activities.

Acknowledgements This research has been financially supported by the Public Policy Research Funding Scheme in Hong Kong (Grant No. 2014. A6.054.15B) and the National Natural Science Foundation of China (Grant No. 71272046). The authors would like to acknowledge the survey respondents for their contribution to this research, and Dan Tan at Tongji University for her valuable assistance in data collection.

\section{References}

Allred C R, Fawcett S E, Wallin C, Magnan G M (2011). A dynamic collaboration capability as a source of competitive advantage. Decision Sciences, 42(1): 129-161 
Barlish K, Sullivan K (2012). How to measure the benefits of BIM-A case study approach. Automation in Construction, 24: 149-159

Bernstein H M (2015). The Business Value of BIM in China. Dodge Data and Analytics, Bedford, MA

Bryde D, Broquetas M, Volm J M (2013). The project benefits of building information modelling (BIM). International Journal of Project Management, 31(7): 971-980

Cao D, Li H, Wang G (2014). Impacts of isomorphic pressures on BIM adoption in construction projects. Journal of Construction Engineering and Management, 140(12): 04014056

Cao D, Li H, Wang G, Zhang W (2016). Linking the motivations and practices of design organizations to implement building information modeling in construction projects: empirical study in China. Journal of Management Engineering, 32(6): 04016013

Cao D, Wang G, Li H, Skitmore M, Huang T, Zhang W (2015). Practices and effectiveness of building information modelling in construction projects in China. Automation in Construction, 49: 113-122

Cao M, Zhang Q (2011). Supply chain collaboration: impact on collaborative advantage and firm performance. Journal of Operations Management, 29(3): 163-180

Chopra S, Meindl P (2001). Supply Chain Management: Strategy, Planning and Operation. Prentice Hall, Upper Saddle River, NJ

Ding L, Zhou Y, Akinci B (2014). Building information modeling (BIM) application framework: the process of expanding from $3 \mathrm{D}$ to computable nD. Automation in Construction, 46: 82-93

Dossick C S, Neff G (2010). Organizational divisions in BIM-enabled commercial construction. Journal of Construction Engineering and Management, 136(4): 459-467

Eastman C, Teicholz P, Sacks R, Liston K. (2011). BIM Handbook: A Guide to Building Information Modeling for Owners, Managers, Designers, Engineers and Contractors (2nd ed.). Hoboken: John Wiley and Sons

Emerson R M (1962). Power-dependence relations. American Sociological Review, 27(1): 31-41

Fornell C, Larcker D F (1981). Evaluating structural equation models with unobservable variables and measurement error. Journal of Marketing Research, 18(1): 39-50

Francom T C, El Asmar M (2015). Project quality and change performance differences associated with the use of building information modeling in design and construction projects: Univariate and multivariate analyses. Journal of Construction Engineering and Management, 141(9): 04015028

Froese T M (2010). The impact of emerging information technology on project management for construction. Automation in Construction, 19(5): 531-538

Gao J, Fischer M (2008). Framework and Case Studies Comparing Implementations and Impacts of 3D/4D Modeling across Projects. Center for Integrated Facility Engineering, Stanford University Stanford, CA

Gattiker T F, Goodhue D L (2005). What happens after ERP implementation: understanding the impact of interdependence and differentiation on plant-level outcomes. Management Information Systems Quarterly, 29(3): 559-585

Giel B K, Issa R R A (2013). Return on investment analysis of using building information modeling in construction. Journal of Computing in Civil Engineering, 27(5): 511-521
Hair J F, Sarstedt M, Ringle C M, Mena J A (2012). An assessment of the use of partial least squares structural equation modeling in marketing research. Journal of the Academy of Marketing Science, 40(3): 414433

Hartmann T, Gao J, Fischer M (2008). Areas of application for 3D and 4D models on construction projects. Journal of Construction Engineering and Management, 134(10): 776-785

Hoegl M, Gemuenden H G (2001). Teamwork quality and the success of innovative projects: a theoretical concept and empirical evidence. Organization Science, 12(4): 435-449

Karimi J, Somers T M, Bhattacherjee A (2007). The impact of ERP implementation on business process outcomes: A factor-based study. Journal of Management Information Systems, 24(1): 101-134

Lamming R C (1996). Squaring lean supply with supply chain management. International Journal of Operations \& Production Management, 16(2): 183-196

Lee G, Lee J, Jones S A (2012). The Business Value of BIM in South Korea. McGraw Hill Construction, Bedford, MA

Li H, Lu W, Huang T (2009). Rethinking project management and exploring virtual design and construction as a potential solution. Construction Management and Economics, 27(4): 363-371

Lopez R, Love P E (2012). Design error costs in construction projects. Journal of Construction Engineering and Management, 138(5): 585593

Lu W, Fung A, Peng Y, Liang C, Rowlinson S (2014). Cost-benefit analysis of Building Information Modeling implementation in building projects through demystification of time-effort distribution curves. Building and Environment, 82: 317-327

Pfeffer J (1982). Organization and Organizational Theory. Pitman, Boston, MA

Pfeffer J, Salancik G R (1978). The External Control of Organizations: A Resource Dependence Perspective. New York: Harper \& Row

Podsakoff P M, Organ D W (1986). Self-reports in organizational research: problems and prospects. Journal of Management, 12(4): 531-544

Poirier E A, Staub-French S, Forgues D (2015). Measuring the impact of BIM on labor productivity in a small specialty contracting enterprise through action-research. Automation in Construction, 58: 74-84

Preacher K J, Hayes A F (2004). SPSS and SAS procedures for estimating indirect effects in simple mediation models. Behavior Research Methods, Instruments, \& Computers, 36(4): 717-731

Preacher K J, Hayes A F (2008). Asymptotic and resampling strategies for assessing and comparing indirect effects in multiple mediator models. Behavior Research Methods, Instruments, \& Computers, 40 (3): 879-891

Rai A, Patnayakuni R, Seth N (2006). Firm performance impacts of digitally enabled supply chain integration capabilities. Management Information Systems Quarterly, 30(2): 225-246

Sacks R, Barak R (2008). Impact of three-dimensional parametric modeling of buildings on productivity in structural engineering practice. Automation in Construction, 17(4): 439-449

Sahin F, Robinson E P Jr (2005). Information sharing and coordination in make-to-order supply chains. Journal of Operations Management, 23(6): 579-598

Scheer L K, Kumar N, Steenkamp J B E (2003). Reactions to perceived inequity in US and Dutch interorganizational relationships. Academy 
of Management Journal, 46(3): 303-316

Shen F Y, Chang A S (2011). Exploring coordination goals of construction projects. Journal of Management Engineering, 27(2): 90-96

Smits W, van Buiten M, Hartmann T (2016). Yield-to-BIM: impacts of BIM maturity on project performance. Building Research and Information (in press)

Ian Stuart F, McCutcheon D (1996). Sustaining strategic supplier alliances. International Journal of Operations \& Production Management, 16(10): 5-22

Succar B (2009). Building information modelling framework: a research and delivery foundation for industry stakeholders. Automation in Construction, 18(3): 357-375

Taylor J E (2007). Antecedents of successful three-dimensional computer-aided design implementation in design and construction networks. Journal of Construction Engineering and Management, 133(12): 993-1002

Volk R, Stengel J, Schultmann F (2014). Building information modeling (BIM) for existing buildings - Literature review and future needs. Automation in Construction, 38: 109-127

Winch G M (2010). Managing Construction Projects: An Information
Processing Approach (2nd ed.). Oxford: Wiley-Blackwell

Won J, Lee G (2016). How to tell if a BIM project is successful: a goaldriven approach. Automation in Construction, 69: 34-43

Wong C W, Lai K H, Cheng T C E, Lun Y H V (2015). The role of ITenabled collaborative decision making in inter-organizational information integration to improve customer service performance. International Journal of Production Economics, 159: 56-65

Yalcinkaya M, Singh V (2015). Patterns and trends in building information modeling (BIM) research: a latent semantic analysis. Automation in Construction, 59: 68-80

Yan T, Dooley K (2014). Buyer-supplier collaboration quality in new product development projects. Journal of Supply Chain Management, 50(2): 59-83

Zhang W, Cao D, Wang G (2008). The construction industry in China: Its bidding system and use of performance information. Journal for the Advancement of Performance Information and Value, 1(1): 6-19

Zhu K, Kraemer K L, Xu S (2006). The process of innovation assimilation by firms in different countries: a technology diffusion perspective on E-Business. Management Science, 52(10): 15571576 